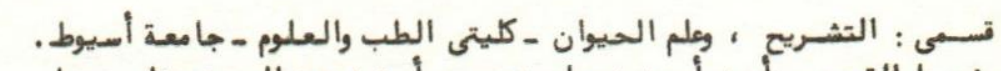

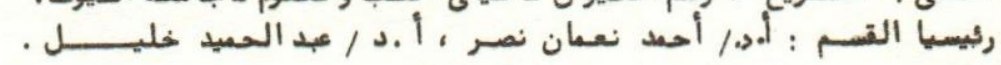

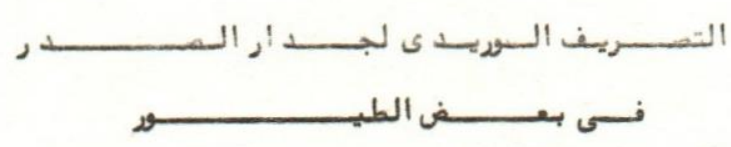

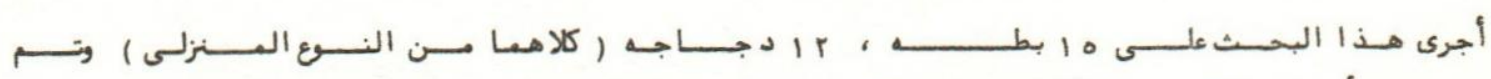

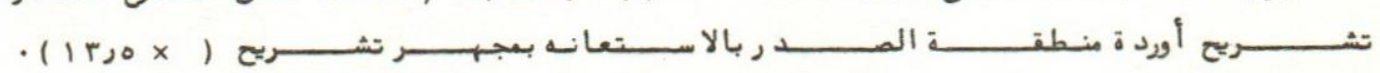

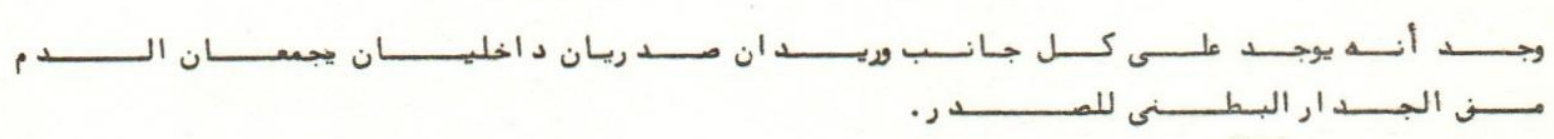

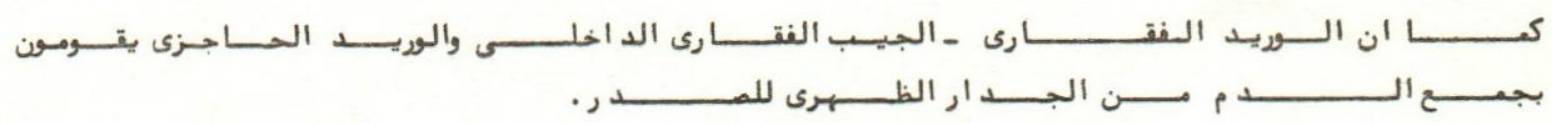

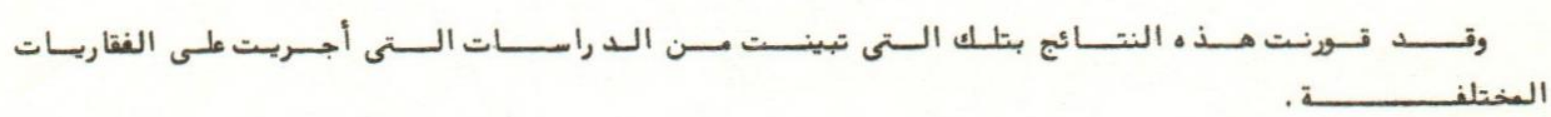


Depts. of Anatomy \& Zoology,

Faculty of Medicine \& Faculty of Science, Assiut University, Head of Depts. Prof. Dr. A.N. Nasr 8 Prof. Dr. A. Khalil.

\title{
VENOUS DRAINACE OF THE THORACIC WALL OF SOME BIRDS (DUCK AND CHICK) (With 4 Figures)
}

\author{
By \\ R.S. MOHAMMED ${ }^{*}$, M.N.M. SALEH ${ }^{*}$, and M.T. WAHBA ${ }^{* *}$ \\ (Received at $28 / 9 / 1980$ )
}

\begin{abstract}
SUMMARY
The present study was done on fifteen adult domestic ducks ( Anas platyrhynchos ) and tweleve adult domestic chicks (Gallus domesticus, rhode island red). It was observed that each side of the ventral thoracic wall was drained by means of two internal thoracic veins. Each side of the dorsal thoracic wall was drained by means of the caudal vertebral vein, the internal vertebral sinus and the septal vein. It was concluded that the internal vertebral sinus, in birds, was analogus with the azygos vein in manmals as both received most of the dorsal intercostal veins. The present work proved the presence of profuse anastomoses between the intercostal veins. These were attributed to the rapid criculation which was caused by the high metabolic rate and consequentely the great activity of birds (BELLARIS and JENKIN, 1960).

The present findings were compared with those obtained by other investigators in different vertebrates.
\end{abstract}

\section{INTRODUCTION}

Birds especially the domestic ones are widley used as experimental animals in medical research.Many published literature, SAUNDERS and MANTON, (1949), BELLARIS and JENKIN, (1960);BRADLEY, (1960);AL-HUSSINI and DEMIAN, (1964); BDE, 1968; BAUMEL, (1975); KING and MCLELLAND, (1975), on the venous system of brids were perused. However all except, BAUMEL (1975), gave no attentin to the veins draining the thoracic walls.

The present study described the veins draining the thoracic walls because these veins are also driectly connected with those of vital organs such as the brain and spinal cord.

\section{MATERIAL AND METHODS}

In the present study fifteen adult ducks (Anas platyrhynchos) and tweleve adult chicks (Gallus domesticus; (rhod island red) were used. The birds were killed with high chloroform anaethesia, in a bell jar. The throacic and abdominal cavities were opened. The birds were preserved in $10 \%$ fromaldehyde solution. The veins were not injected as the clotted blood acted as an injection mass.

All abdominal viscera as well as the heart and lungs were removed carefully. The first thoracic vertebra was identified and used as a landomark from which other thoracic vertebrae were counted. The intercostal spaces, their boundaries and the veins draining them were identified. With the aid of a bone nippling forceps, the laminae of all vertebrae were removed to expose the internal vertebral sinus and the different veins connected with it.

An outline of the inner aspect of the thoracic wall, showing the intercosal spaces and their draining veins, was drawn. The same was done for the dorsal aspect of the dorsal thoracic wall and the adjacent part of the neck, showing the spinal cord, the vertebrae and the rib stumps, was drawn. Mimeographed copies of these outline were made and used to record the results (SEIB, 1932). The veins, under investigation, were drawn with regard to their relative size and bony relations.

The terms for avian anatomy and orientation used were according to Nomina Anatomia Avium of I.C.A.A.N. (1975).

RESULTS

1- DUCK

THE Intercostal Spaces

There were seven intercostal spaces in duck. Each space had two ventral intercostal veins and single dorsal 


\section{R.S. MOHAMMED, et al.}

one. (Fig. 1). The two ventral intercostal veins, a cranial vein present along the caudal border of the numerically corresponding rib and a caudal one present along the cranial border of the next rib (Fig. 1). The dorsal intercostal vein was present along the cranial border of the next rib.

the Venous drainage of the Ventral thoracic wall

\section{The Internal Throacic Veins:}

There were two internal thoracic veins on each side; a ventral vein and dorsal one (Fig. 2).

The ventral internal thoracic vein began opposite the sternal end of the last rib as a direct continuation of the cranial epigasteric vein. Dorsal to all ribs, the vein passed cranially along the sternal margin, crossed the first rib, and terminated immediately into the corresponding subclavian vein in company with the dorsal internal thoracic vein (Fig. 2). The ventral internal thoracic received the ventral ends of the ventral intercostal veins of all spaces and also samll veins from the back of the sternum.

The dorsal internal thoracic vein arose opposite the last rib by confluence of small veins from the adjacent all ribs. Finally, it opened into the corresponding subclavian vein. The dorsal internal thoracic vien received the dorsal ends of all'ventral intercostal veins (Fig. 2).

Profuse anastomotic venous channels were present between the ventral intercostal veins of adjacent spaces. Some of them were short and connected the veins of adjacent two spaces. Others were long and connected the veins of three or four spaces. An example of the latter was that present just dorsal to the dorsal internal thoracic vein (Fig. 2). It joined the dorsal internal thoracic vein at the level of the fourth intercostal spaces.

\section{The Venous Drainage of The Dorsal Thoracic Wall:}

Each dorsal intercostal vein began about the middle of the space. It ran medially along the cranial border of the next rib (Fig. 1\&2). The first one became continous cranially as the caudal vertebral vein. Each of the remaining ones, on reaching the vertebral column, entered the vertebral canal through the corresponding intervertebral foramen to open into the internal vertebral sinus (Fig. 2\&3). Each dorsal intercostal vein received the collateral vein which passed medially along the caudal border of the next rib. Just before reaching the vertebral column, it turned cranially to passe through the forked vertebral end of the $r i b$ and opened into its parent trunk (Figs.1\&2). The dorsal intercostal vein also received veins from the adjacent muscles and verebrae.

Profuse anastomoses between the adjacent dorsal intercostal veins were seen. In one specimen, a longitudian anastomotic channel, connecting the dorsal intercostal veins, was seen alongside the vertebral columin.

\section{The Caudal Vertebral Vein:}

The caudal vertebral vein, orginated as the direct continuateon of the first dorsal intercostal vein, ran cranially along the vertebral column, to the first rib where it passed through its forked vertebral end to terminate into the vertebral vein in common with the cranial vertebral vein ( Fig. 2 ). In addition to its collateral tributary, it received a vein present along the caudal border of the first rib. In two specimens, the caudal vertebral vein received also the second dorsal intercostal vein.

\section{The Internal Vertebral Sinus:}

The internal vertebral sinus was present along the middorsal line of the spinal cord(Fig.3). It extended from the foramen magnum to the level of the last thoracic vertebra. Cranially the sinus was directly communicated with the occipital and marginal cranial venous sinuses. Caudally it communicated with the ilio-femoral vein through two small veins. Each of the latter arose from the caudal end of the sinus and passed ventrally across the side of the last thoracic vertebral to open into the corresponding ilio-fermoral vein. The internal vertebral sinus received all dorsal intercostal veins except the first (Fig. 3).

At the root of the neck; on each side, there were two veins connecting the internal vertebral sinus to the vertebral vein (Fig. 3). These veins were termed the cranial and caudal communicating veins. The cranial communicating vein arose from the caudal part of the cervival segment of the sinus. It passed out the vertebral canal through the nearly intervertebral foramen. It ran medially to join the vertebral vein either directly or through the cranial vertebral vein. The caudal communicating vein arose form the cranial end of the thoracic segment of the sinus. It left the vertebral canal through the nearly intervertebral foramen(usually present between the first and second thoracic veterbral), ran medially to terminate into the vertebral vein.

Assiut Vet.Med.J.Vol. 8, No. 15816,1981 . 
The Septal Vein:

The septal vein arose from the fifth dorsal intercostal (Fig. 2), passed caudally on the dorsal thoracic wall until it reached the seventh rib. It continued ventromedially, pierced the pleuro-peritoneal septum and opened in the caudal vena cava.

\section{II- $\mathrm{CHICK}$}

There were five pairs of intercostal spaces (Fig. 4). Otherwise, results present here were nearly simillar to those obtained in duck.

\section{DISCUSSION}

the Venous draigage of the ventral throacic wall

\section{The Internal Thoracic Veins:}

In relation to the number, the present study showed that there were two internal thoracic veins, a ventral vein and a dorsal one, on each side. Similar results were obtained by BAUMEL (1975) in birds.

As regards the origin of the internal thoracic veins, the present work proved that the ventral vein began as a direct continuation of the cranial epigasteric vein while the dorsal one arose as a result of the confluence of small veins from the muscles of the ventral abdominal wall.

Regarding the mode of termination, the present work showed that the ventral and dorsal internal throacic veins terminated usually by a common opening into the subclavian vein. BAUMEL (1975) in birds stated that the larger vein opened into the crainal vena cava, while the smaller one joined the pectoral or sternoclavicular which were tributaries of the cranial vena cava.

TYLOR and WEBER (1956) and WEICHERT (1958), in cat, MILLER et al. (1964), in dog and WARWCK and WILLIAMS (1973), in man, stated that the ventral thoracic wall was drained by two internal thoracic veins, one on each side.

On the other hand, the internal thoracic veins were completely absent in the remaining vertebrates such as fishes, amphibians and reptiles. Their place was taken either by the two lateral abdominal veins, in elasmobranch fishes, or by a single mid-ventral abdominal vein, in lung fishes, amphibians and reptiles (WEICHERT, 1958; TORREY, 1961; ROMER, 1962). These veins collected the venous blood from the whole of the ventral body wall.

From the above mentioned data, it can be concluded that the internal thoracic veins were present only in birds and mammals. In birds (duck and chick), these veins were simillar in all respects.

\section{the Venous drainage of the dorsal thoracic wall}

The Caudal Vertebral Vein:

MILLER (1903), in chick, stated that all dorsal intercostal veins were teceived by the (posterior) vertebral vein. The latter opened into the corresponding (precava) in common with the internal jugular and subclavian veins. Depending upon this statment MCCLURE (1906) concluded that the (posterior) vertebral vein was analogus with the azygos vein in mannals. The present study illusterated that the caudal vertebral vein received the first dorsal intercostal vein only. Therefore it can be concluded that the caudal yertebral vein, in birds is not analogus with the azygo vein in mammals, but represents the superior intercostal vein in cat (WERCHERT, 1958) and the vena intercostalis prima in pethicus rhesus (SEIB, 1932).

\section{The Internal Vertebral Sinus:}

The present work revealed that the internal vertebral sinus received the dorsal intercostal veins from the second to the last, inclusive. The same findings were obtained by BAUMEL ( 1973), in birds. McCLURE ( 1903) in didelphys, TYLOR (1956) in cat, COOK (1965) in Laboratory mouse, MILLER et al., 1964) in dog found an azygos vein. SEIB (1932), in pethicus rhesus, and WARWICK and WILLIAMS (1973) in man proved the presence of azygos, hemiazygos and accessory hemiazygos veins. These veins were present in close relation to the vertebral column and received most of the dorsal intercostal veins. As proved by the present study, neither the azygos nor the hemiazygos veins were present in birds. To interprete this difference, it is worth to mention that two supracardinal veins appeared in early embryonic life of mammals. These veins were responsible for the appearance of azygos veins (McCLuRE, 1906; 


\section{R.S. MOHAMMED, et al.}

HUNTINGTON and MCCLURE, 1920; NELSEN 1953 and HAMILTON and MOSSMAN, 1972), but they never develop in avian embryos (LILLIE, 1930; PATTEN, 1948). Hence azygos veins were absent in birds.

The venous system draining the dorsal intersegmental veins in fishes and amphibians was more primitive than that met with in birds and-mammals. In 1958, WEICHERT stated that these veins opened into the posterior cardinal veins. In reptiles, different observations were noticed. WEICHERT (1958) postulated that the dorsal intersegmental veins terminated into two posterior vertebral veins which were developed from the anterior parts of the two postcardinals. In grass snake and lizards, SAUNDERS and MANTON (1949) mentioned that an azygos vein, representing the right posterior cardinal vein, drained the dorsal intersegmental veins of bothsides.

The present study proved the presence of profuse anastomoses between the intercostal veins. This result was confirmed by BELLARIS and JENKIN (1960), in birds. They attributed these profuse anastomoses to the high metabolic rate and rapid circulation.

\section{REFERENCES}

Al-Russaini, A.H. and Demian, E.S. (1964): Practical animal biology (2nd ed.) , Vol. 2, Dar Al-Maaref, Cairo.

Baumel,J.J. (1975): Aves heart and blood vessels. In the anatomy of the domestic animals (ed. Getty, R.) (5th ed.) Vol. 2, พ.B. Saunders Company, Philadelphia, London \& Toronto.

Bellaris,A.D.A., and Jenkin,C.R. (1960): The circulatory system. In biology and comparative physiology of birds. (ed. Marshall,A.J.), Vol. 1, Academic Press, INC., New York.

Bradley,O.C. (1960): The structure of the fowl (4th ed.) Oliver and Boyd, Edinburgh and London.

Cook, M.J. (1965): The anatomy of the Iaboratory mouse. Academic Press, London and New York.

Ede,D.A. (1968): Bird structure, Hutchinson Educational LTD, London.

Hamilton,W.J. and Mossman,H.W. (1972): Human embryology ( 5 th ed.)., The Macmillan Press LTD, The Williams and Wilkins Company, Cambridge.

Huntington,G.S. and McClure,C.F.W.(1920):The development of the veins in the domestic cat,with special reference, 1- to the share taken by the supracardinal veins in the development of the postcava and the azygos veins and 2- to the interpretation of the variant conditions of the postcava and its tributaries, as found in the adult. Anat. Rec., 20, pp: 1-30.

King,A.S. and McLelland,J. (1975): Outline of the avian anatomy, Bailliere Tindall, London.

Lillie,F.R. (1930): The development of the chick. (2nd ed.). Henry Holt, New York.

McClure,C.F.W. (1903): A contribution to the anatomy and development of the venous system of Didelyphys marsupialis Part 1, anatomy. Am. J. Anat., Vol. 2, No. 3, pp: 15-65.

McClure,C.F.W. (1906): A contribution to the anatomy and development of the venous system of Didelphys marsupialis Part II, Development. Am. J. Anat., Vol. 5, pp: 163-225.

Miller,A.M. (1903): The development of the postcaval vein in birds. Am. J. Anat., Vol.; 2, pp: 283-310.

Miller,M.E., Christensen,G.C. and Evans,B.E. (1964): Anatomy of the dog, W.B. Saunders Company, Philadelphia and London.

Neisen,O.E. (1953): Comparative embryology of the vertebrates, The Blakiston Company, INC. New York and Toronto.

Nomina Anatomia Avium (1975): International Committe on Avian Anatomical Nomenclature, World Association of Vet. Anatomists. (Cited by Getty, R., 1975).

Patten,B.M. (1958): Foundation of embryology. McGraw-Hill Book Company, INC., New York, London and Toronto.

Romer,A.S. (1962): The vertebrate body. (3ra ed.) Vakils, Feffer and Simons Private LTD. Bombay, India.

Saunders,J.T. and Manton,S.M. (1949): A manual of practical vertebrate morphology ( 2 nd ed. ), Oxford University Press, London.

Seib,G.A. (1932): On the azygos veins in Pithecus rhesus. Anat. Rec., Vol. 51, pp: $285-298$.

Torrey,w.T. (1961): Morphogenesis of the vertebrates. (2nd ed.) John Wiley and Sons, INC. New York and London.

Tylor,W.T. and Weber,R.J. (1956): Functional mamnalian anatony, D. Van Nostrand Company, INC., Princeton, New York Jersy-Toronto, New York and London.

Warwick,R. and Williams,P.L. (1973): Gray's anatomy, (35th ed.). Jarrold and Sons, Norwich.

Weichert,C.K. (1958): Anatomy of the chordates. (2nd ed.), McGraw-Hill Book Company, INC., New York and London. 


\section{ABREVIATIONS}

\begin{tabular}{|c|c|}
\hline T.V. & : Thoracic vertebra \\
\hline R. & : Rib. \\
\hline St. & : Sternum. \\
\hline Vent. I.T.V. & : Ventral internal thoracic vein. \\
\hline D.I.T.V. & : Dorsal internal thoracic vein. \\
\hline J.V. & : Jugular vein. \\
\hline Sc.v. & : Subclavian vein. \\
\hline Cr. ep.V. & : Cranial epigasteric vein. \\
\hline Cr.ver.v. & : Cranial vertebral vein. \\
\hline Cr.Cc.v. & : Cranial communicating vein. \\
\hline Cd.Ver.v. & : Caudal vertebral vein. \\
\hline Cd.Cc.v. & : Caudal communicating vein. \\
\hline V.C.Cr. & : Vena Cava Cranialis. \\
\hline D.Ic.V. & : Dorsal intercostal vein. \\
\hline Sep.V. & : Septal vein. \\
\hline v.c.ca. & : Vena Cava Caudalis. \\
\hline I.F.V. & : Ilio fermoral vein. \\
\hline Cr.Vent.Ic.V. & : Cranial ventral intercostal vein. \\
\hline Cd.Vent.Ic.V. & : Caudal ventral intercostal vein. \\
\hline Ver.Col. & : Vertebral column. \\
\hline Int. Ver.s. & : Internal vertebral sinus. \\
\hline Sp.Cd. & : Spinal cord. \\
\hline Co.v. & : Collateral vein. \\
\hline
\end{tabular}

\section{AXPLANATION OF FIGURES}

Fig. 1: A diagram of the right third intercostal space of the duck showing its boundaries and pertiained veins.

Fig. 2: A diagram of a ventral aspect of the right half of the thoracic wall of duck showing the intercostal spaces and their draining veins.

Fig. 3: A diagram of a dorsal aspect of all thoracic and last cervival vertebrae of duck, after removal of their laminae, showing internal vertebral sinus (Int. Vers.s.) and veins connected with it; dorsal intercostal veins (D.lC.V) and Cranial and caudal communicating veins (Cr. Cc. $\mathrm{V} \& \mathrm{Cd}$. Cc. V.).

Fig. 4: A diagram of a ventral aspect of the right half of the throacic wall of chick showing the intercostal spaces and their draining veins. 


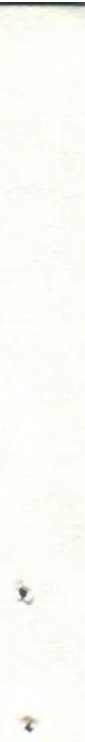


(1)

( RIGHT )

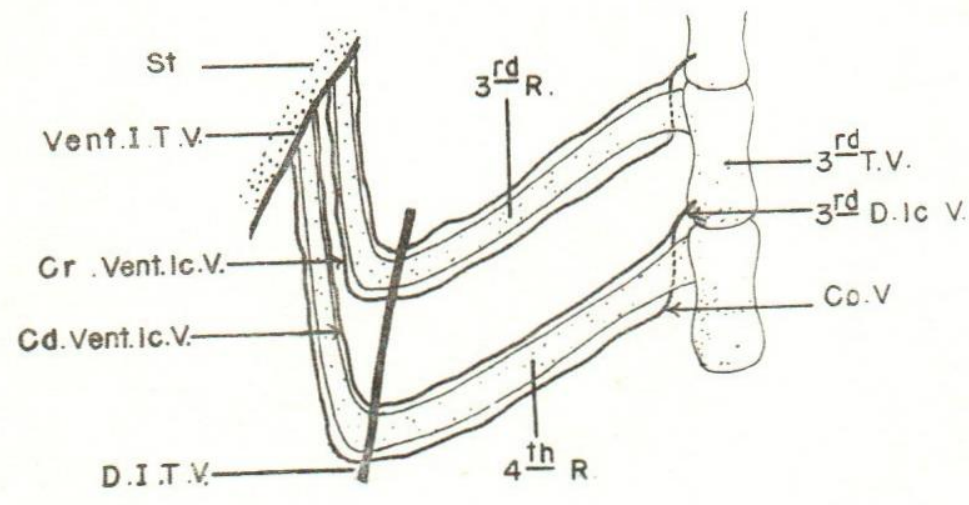

(3)

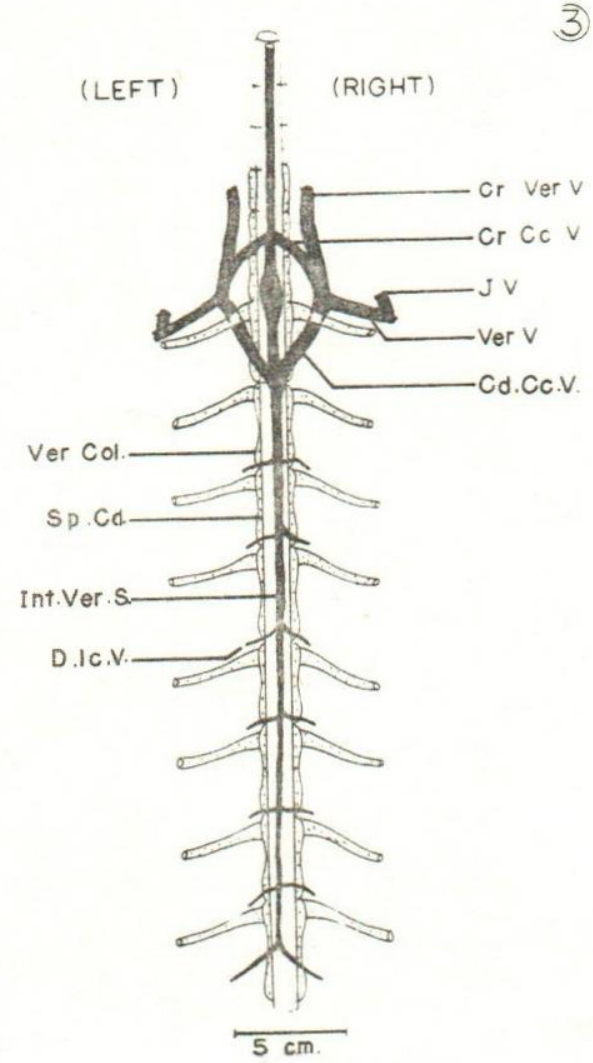

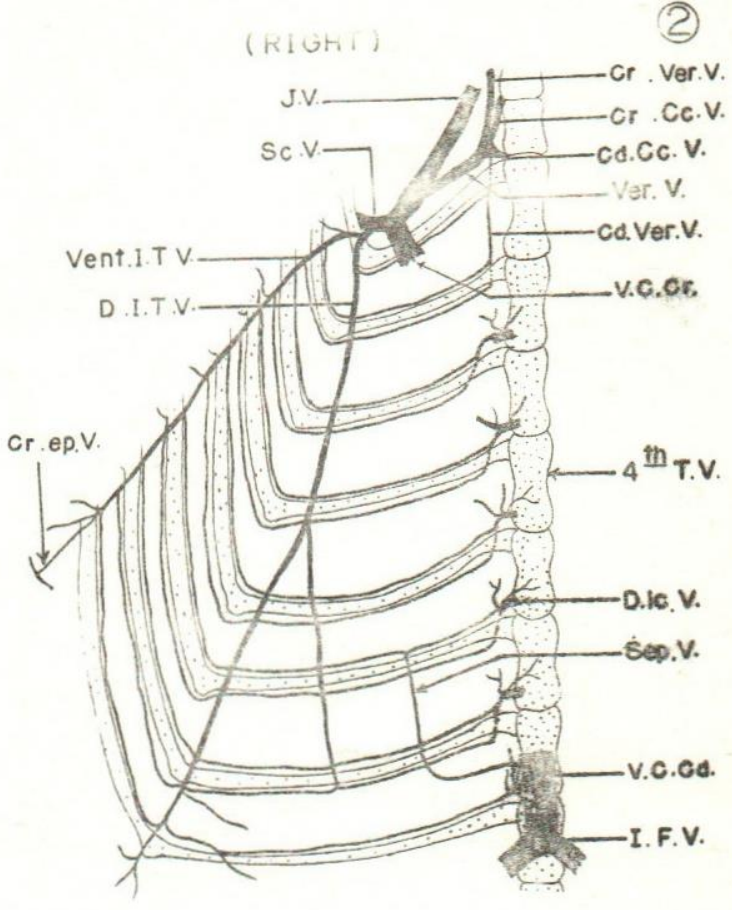

$5 \mathrm{~cm}$

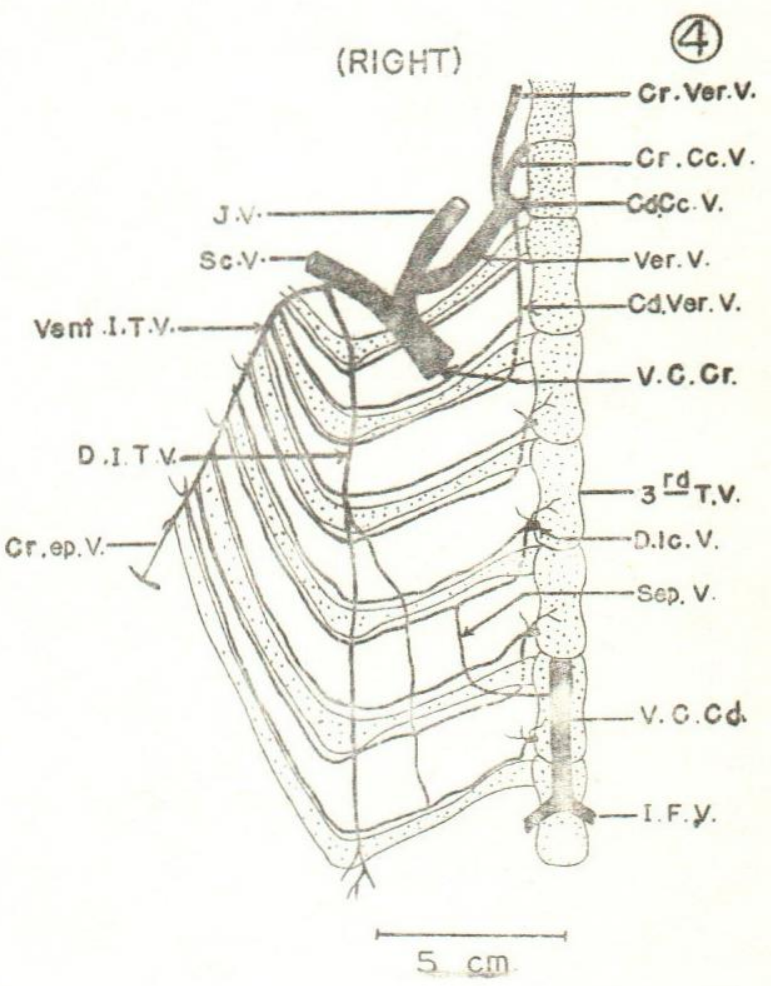


2

$-$ 